\title{
Construyendo al enemigo. El escrito antimasónico en la España del siglo XVIII
}

\author{
Building the enemy. \\ The anti-Masonic writing in eighteenth-century Spain
}

\author{
Felipe Santiago del Solar \\ Universidad París Diderot-París 7, Francia \\ fdelsolar@hotmail.com
}

Recepción: 15 de octubre de 2017/Aceptación: 8 de noviembre de 2017

doi: https://doi.org/10.15517/rehmlac.v9i2.31607

Palabras clave

Antimasonería; esfera pública; sociedad civil; producción escrita; prensa.

Keywords

Anti-Freemasonry; Public Sphere; Civil Society; Written Production; Press.

Resumen

Desde mediados del siglo XVIII el espectro de la masonería rondó por el Imperio español. A pesar de que este tipo de sociabilidad no tuvo una implantación efectiva hasta la invasión napoleónica, el escrito antimasónico ingresó tempranamente en la península y, desde allí, a sus colonias Posteriormente, con el advenimiento de la revolución, el espectro de la masonería sirvió como un elemento explicativo del cambio político y como uno de los ejes del discurso reaccionario contra el liberalismo. De este modo, nuestro objetivo es analizar la circulación del escrito antimasónico en la Europa de las luces identificando la especificad de la producción hispánica y su mutación durante el periodo revolucionario. Para ello, se analizarán las obras de autores como José Torrubia y Lorenzo Hervás y Panduro, así como también, la profusa producción periodística publicada entre 1810 y 1830 en ambas riveras del Atlántico.

\begin{abstract}
The specter of Freemasonry haunted the Spanish Empire since the mid- $18^{\text {th }}$ century. Although this kind of sociability was not efficiently implemented until Napoleon's invasion, anti-masonic publications made an early appearance in the Iberian Peninsula and from there into its colonies. Afterwards, with the arrival of the revolution, the specter of Freemasonry was used as an explanation for the political change and as one of the axis of reactionary discourses against liberalism. Thus, our objective is to analyze the circulation of anti-masonic writings in the European era of the Enlightment, specifically the hispanic production and its mutation during the revolutionary period. In order to do so we have studied the works of authors such as José Torrubia and Lorenzo Hervas y Panduro, as well as the vast press production belonging to the period between 1810 and 1830 on both sides of the Atlantic.
\end{abstract}

\section{Introducción}

Desde mediados del siglo XVIII el espectro de la masonería rondó por el Imperio español. A pesar de que este tipo de sociabilidad no tuvo una implantación efectiva hasta la ocupación napoleónica, el escrito antimasónico ingresó tempranamente en la Península, y desde allí, pasó a sus colonias. 
Si bien el modelo literario francés e italiano sirvió de referente, el impreso antimasónico hispánico asumió una fisonomía propia de gran plasticidad, lo que le permitió evolucionar en el tiempo y adaptarse a diferentes circunstancias.

De este modo, la literatura antimasónica producida en el Imperio español desde mediados del siglo XVIII se desarrolló en dos fases que se fueron superponiendo entre sí: en primer lugar, la masonería fue comprendida como una nueva secta emparentada con las herejías bíblicas, y en un segundo momento, el masón fue identificado con el filósofo, agente de la modernidad ilustrada.

Nuestra intensión es presentar una visión panorámica de este proceso de construcción social del "enemigo" masón, considerando los debates europeos en la materia, así como las influencias, apropiaciones y usos que tuvo en el mundo hispánico.

\section{Herejes y libertinos ${ }^{1}$}

Los escritos antimasónicos hispánicos se iniciaron en $1747^{2}$. En términos generales, podemos dividir la producción en dos tipos: referencias anexas a obras que tratan sobre otras temáticas, y libros que abordan exclusivamente la masonería. En ambos casos, todas las obras fueron escritas por sacerdotes y contaban con las debidas autorizaciones reales, convirtiéndolas en literatura oficial a diferencia de los impresos masónicos del resto de Europa que tenían un carácter clandestino ${ }^{3}$.

El primer corpus está compuesto por seis escritos publicados entre 1747 y 1753. Posee cierto grado de cohesión interna en la medida que cada impreso nuevo incorporó al anterior o al menos hizo referencia de este. A pesar de que poseen algunos elementos originales, están fuertemente influenciados por la literatura producida en Italia, fundamentalmente por las bulas papales.

Si bien se trata de impresos de divulgación, todo parece indicar que estaban dirigidos fundamentalmente a sacerdotes, de tal manera de instruirlos con argumentos teológicos para refutar las máximas masónicas, así como también, desmentir las

\footnotetext{
${ }^{1}$ Ferrer Benimeli ya ha realizado un análisis general de los escritores antimasónicos de la primera mitad del siglo XVIII. Sin embargo, nuestro propuesta es complementaria a la anterior, en la medida que la pregunta que guía el análisis es diferente. Al respecto véase José Antonio Ferrer Benimeli, La masonería Española en el siglo XVIII (Madrid: Siglo XXI editores, 1986).

${ }^{2}$ Se suele señalar como primer texto antimasónico en España el libro Muro invencible mariano contra los tiros de un murador disfrazado (1747) de fray Domingo de San Pedro de Alcántara. Sin embargo, luego de revisar el texto no encontramos ninguna referencia a la masonería, sino más bien, criticas a Muratore. De hecho, en la época que se publicó este libro, igualmente se prestó para equívocos tal como queda en evidencia en una carta enviada por Mayans al Nuncio apostólico: "Yo extraño mucho que se permita que se trate tan indignamente un varón tan benemérito de la cristiandad, pues me avisan que ha salido a luz un libro intitulado: Muro invencible Mariano contra los tiros de un murador disfrazado que en buen romance es contra un franco masón (...) injuria verdaderamente detestable. Y quien así habla en el título no puede dejar de decir dentro del libro cosas detestables y dignas de censura teológica", citado por Antonio Mestre, "Muratori y la cultura", en La fortuna di L. A. Muratori, ed Leo Olschki (Modena: Atti del Convegno Internazionale di Studi Muratoriani, 1972).

${ }^{3} \mathrm{Al}$ respecto véase magnifico trabajo de Robert Darton, Edición y subversión. Literatura clandestina en el Antiguo Régimen (México DF: Fondo de Cultura Económica, 2003).
} 
representaciones de honorabilidad y respeto a la religión con que los masones se proyectaban en el orbe europeo. De hecho, el impreso hispánico se inscribió en un espacio de circulación católico conformado por Italia, España y en menor medida Portugal y Bélgica, haciendo de la literatura antimasónica un vehículo de difusión y profundización doctrinal de las condenas pontificias.

Es por ello que los autores de estos impresos fueron en su mayoría sacerdotes eruditos, doctores en teología, calificadores del Santo Oficio y hombres de ciencia, quienes además de publicar sus obras, hacían de mediadores culturales al incorporar, debidamente expurgados, los contenidos de algunos textos antimasónicos de circulación europea.

Se trata, pues, del pronunciamiento oficial de las autoridades eclesiásticas y políticas del Imperio español, quienes a través de sacerdotes emitieron un juicio dogmático respecto a la masonería y a las representaciones en pugna que circulaban en torno suyo. Simbolizan igualmente un apoyo decidido al magisterio romano y un alineamiento político con el Vaticano.

En términos de contenido, los textos presentan elementos análogos, fundamentalmente intentan insertar la condena a la masonería en la larga duración, como una práctica inscrita en la tradición bíblica de lucha y persecución de sectas y herejías.

En lo referente a los autores y sus obras, la primera publicación fue un texto anexo al libro "Opúsculo Moral" perteneciente al agustino José Faustino Cliquet ${ }^{4}$. Su trabajo, además de ser un vehículo de difusión y respaldo a la condena pontificia de Clemente XII, buscaba impugnar cinco proposiciones que el autor atribuye a los masones, a quienes acusa de transgredir y reivindicar faltas a la moral sexual, principalmente la libertad de fornicación. Es así que se homologa la figura del masón con la del "libertino", ya que estos para el autor: "son tan inclinados a la lujuria, defienden con tenacidad, que la fornicación se puede cohonestar, y depurar de su malicia por el motivo de extrema necesidad, y que no sea pecado"5.

Igualmente, se refiere a los masones como herejes y como una "secta perniciosa y pestilencial", anunciando el carácter de "secta herética" que asumirá la masonería en el Imperio español.

El tema de la masonería parece más bien una excusa para desarrollar materias de moral sexual, apoyándose constantemente en su libro La Flor de la Moral, y utilizando a los masones como un "otro" antagónico al ideal de castidad de la Iglesia católica.

\footnotetext{
${ }^{4}$ Existe divergencia respecto a la fecha exacta de publicación. Ferrer Benimeli, por ejemplo, la establece en 1752 como un anexo al libro Tyrosinio Moral. En el diccionario Hijos Ilustres de Madrid, en cambio, aparece como fecha de edición 1749 como anexo al segundo tomo de Flor de la Moral. Nosotros hemos utilizado la versión de 1787 anexa a "Opúsculo".

${ }^{5}$ José Faustino Cliquet, Juicio dogmático moral sobre las cinco proposiciones de la perniciosa secta de los que se llaman De Liberi Muratori, o Francs Masons, Todas heréticas y abominables, condenadas por el SS.P. Clemente XII. Año de 1738 (Madrid: Imprenta de la Viuda de Ibarra, Hijos y Compañía, 1787), 113.
} 
A pesar de la singularidad de los aspectos sexuales desarrollados por el autor, los cuales seguirán presentes en obras posteriores, pero de forma más moderada, Cliquet recomienda a quienes deseen profundizar en la materia el libro del sacerdote José Santa Marta Henriques publicado en Portugal en $1744^{6}$, lo que da cuenta de la interconexión de los impresos católicos y explica, en parte, la unidad argumental con que buscan impedir la proliferación de la masonería en sus reinos.

En 1751 se intensificó el número de publicaciones a raíz de las condenas contra la masonería, lo que demuestra que los impresos estaban destinados a profundizar teológicamente la bula papal, así como también, dar a conocer la disposición real. En el primer aspecto, reviste especial interés la traducción y edición de una carta pastoral publicada en 1751 por el obispo de Vitimilla Pedro María Justiniani ${ }^{7}$, la cual fue reproducida en Barcelona y luego en la Obra de Fray Joseph Torrubia en Madrid ${ }^{8}$.

Una vez más queda en evidencia el espacio de circulación del impreso antimasónico católico, cuyo centro de producción se encontraba en Italia haciendo de España un satélite y una caja de resonancia de la política pontificia.

La pastoral, está estructurada siguiendo tres objetivos: 1-. negar las aseveraciones que los masones hacían de sí mismos en sus escritos; 2-. demostrar qué sus prácticas eran contrarias a la fe; 3-. reforzar los argumentos pontificios para su condena.

En el primer punto, niega la afirmación de que en sus asambleas no suceda nada contrario a la fe ni a la corona. Para ello, destaca como parte constitutiva de las ceremonias masónicas el uso del secreto, del cual insinúa que tiene por objetivo esconder el libertinaje, ya que "Los deleites carnales siempre aman las tinieblas". En lo relativo a las asambleas, cuestiona que se reúnan personas de diferentes religiones, pero sobretodo, que se realice un juramento bajo la amenaza de muerte para quienes lo transgredan.

En términos generales, para Justiniani los masones proyectan una imagen distorsionada de sí mismos, debido a que tienen por máxima mentir, y de esta manera

\footnotetext{
${ }^{6}$ José Santa Marta Henriques, Trutina Theologico- Polemica, seu Dogmatica, et Moralis, ad quam revocantur juxte pondus sanctuarii quinque Propositiones Muratorum, vulgo dos Pedreiros Livres (Evora: Tip. Da Academia, 1744).

${ }^{7}$ Pier Maria Giustiniani, nació en Chio (isla de Scio) en 1693. A temprana edad ingresó al monasterio de Montecassino, posteriormente realizó su preparación teológica y canonista en el colegio de San Anselmo en Roma, donde fue ordenado como Benedictino. Se desempeñó como lector en el distrito canónico de Montecasino, Casena y Ravenna, fue igualmente archivista de la basílica de San Paolo, consultor del Santo Oficio y examinador sinodal en Casena. En 1726 fue nombrado obispo de Sagona (Francia) y en 1741 obispo de Vitimilla (Italia) lugar este último donde falleció en 1765. Al respecto véase: Anónimo, Secoli Cristiani della Liguria (Torino: Tipografia Chirio e Mina, 1843), 523.

${ }^{8}$ El texto original fue publicado el 25 de mayo de 1747 con el titulo: "Istruzione pastorale intorno alla Società dei Francs- Maçons o dei liberi muratori". Resulta sorprendente el impacto que causo en España, en un contexto que en Italia no tuvo mayor trascendencia. A respecto véase: Carlo Francovich, Storia della Massoneria in Italia. Dalle origini alla rivoluzione francese (Firenze : La Nuova Italia, 1974), 63.

${ }^{9}$ Joseph Pi y Vila- Rasa, Carta pastoral que escribió el ilustrissimo y Rmo. Señor Don Fr. Pedro Maria Giustiniani, Obispo de Ventimiglia en el Estado de Génova, en orden a la Sociedad de los Francmassones (Barcelona, 1751), 9.
} 
ocultar sus verdaderas doctrinas que consisten en: defender que la simple fornicación es lícita, promover el vicio, argüir que no están obligados a los preceptos de la Iglesia y despreciar con obstinación y contumacia la excomunión fulminada en la Bula pontificia la cual, para el autor, constituye un justo castigo:

Les hubiera separado de la participación del preciosísimo cuerpo y sangre de Jesucristo y de la sociedad de los fieles?, les hubiera excluido de la comunión de la Santa Madre Iglesia y unión en el cielo y les hubiera juzgado en tierra, condenándoles con el Diablo y todos los ángeles apostatas y todos los réprobos de fuego eterno ${ }^{10}$.

Detrás del argumento está presente la acusación de herejía. De hecho, gran parte de la pastoral está fundamentada con citas bíblicas y parajes que insertan a los masones en la lógica del combate de la Iglesia contra los gentiles ${ }^{11}$.

El mismo año apareció en una línea análoga la obra "Adumbratio Liberorum Muratorum" de Juan Madre de Dios, lector de teología y secretario general de la Orden de Descalzos de la Santísima Trinidad.

Este impreso, a pesar de estar escrito en latín, y por ende estar dirigido a un restringido número de personas, tiene la virtud de utilizar un aparato bibliográfico relativamente exhaustivo. De hecho, en la introducción menciona que ha consultado la pastoral de Justiniani, una relación publicada en Nápoles en 1746 por Valerio Angiolieri Alticozi ${ }^{12}$, la obra de Banier y Le Mascrier ${ }^{13}$ y las Bulas de Clemente XII y Benedicto $\mathrm{XIV}$, convirtiéndose en la primera síntesis del saber católico referente a la masonería.

La obra de Juan Madre de Dios, al igual que los escritos que le precedieron, buscaba homologar a la masonería con las sectas bíblicas, principalmente con basilidianos, gnósticos y audeanos ${ }^{14}$.

Para el autor, la masonería no era más que el rescate de antiguas idolatrías y supersticiones, las cuales desde tiempos remotos habían sido prohibidas, ya sea por el derecho romano o por edictos dictados en su contra, tal como sucedió con los templarios y las medidas dictadas por Clemente $\mathrm{V}$ en 1311.

En la misma línea se encuentra el impreso "Verdadera cronología de los maniqueos que aún existen con el nombre de Francmasones"15, en el cual el autor busca vincular en la larga duración la labor de los reyes de España para erradicar la herejía.

\footnotetext{
${ }^{10}$ Pi y Vila- Rasa, Carta pastoral, 32.

${ }^{11}$ Las fuentes más utilizadas son San Juan y San Pablo, principalmente aquellos parajes en los cuales corrigen del error a judíos y gentiles.

${ }^{12}$ Valerio Angiolieri Alticozzi, Relazione della compagnia de liberi Muratori, estratta da varie Memorie, e indirizzata all' Abate Carl' Antonio Giuliani (Napoli, 1746).

${ }^{13}$ Histoire générale des cérémonies, mours, et coutumes religieuses de tous les peuples du monde, représentés en 243 figures dessinées de la main de Bernard Picard: Avec des explications historiques y curieuses, par M. L'Abbé Banier, de l'Académie Royale des Inscriptions et Belles-Lettres, et par M. L'Abbé le Mascrier (París: chez ROLLIN fils, quay des Augustins, á Saint Athanase et au Palmier, 1741). ${ }^{14}$ Johanne Matre Dei, Adumbratio Liberorum Muratorum, seu Francs-Massons, vi cujus eorum societas, Origo, Ritus, Mores \&c. Detenguntur (Madrid, 1751), 33.
} 
El aspecto más relevante de este escrito, es que se trata del primer texto que vincula a los masones con el jansenismo, relación que tomará mayor fuerza luego de la Revolución francesa. Al respecto el autor señala:

Viéndose ya estos herejes muy faltos de fuerzas vinieron a sembrar sus errores, y a vueltas y pretextos de los Jansenistas se introdujeron en el Reino de Francia, bajo el titulo y simple nombre de Franc-Masones tentaron al cristianísimo rey Luis decimo quinto, pero este príncipe defensor los persiguió, y por esto volvieron a dejar el nombre, y con el de Jansenistas tienen sus juntas secretas por más que se les persigue ${ }^{16}$.

En 1752 apareció el libro de mayor impacto en el mundo hispánico "Centinela contra Francmasones"17, impreso que sintetiza todo el saber antimasónico católico que circulaba en Europa.

La autoría corresponde al erudito sacerdote Joseph Torrubia, quien fue misionero en Filipinas y América Latina, calificador y revisor del Supremo Consejo de la Inquisición, Cronista General y Archivero General de la Orden de San Francisco ${ }^{18}$.

Torrubia, fue un hombre de letras y de ciencias. Además de ser perito en "la lengua natural de Filipinas", fue revisor de la Inquisición en lengua francesa e Italiana. Igualmente destacable fue su producción literaria, en la cual abundan traducciones de obras religiosas, tratados con descripciones de Filipinas y América Latina, obras de apología, vida de santos y libros de ciencias, de donde destaca "Aparato para la Historia Natural Española” de $1754^{19}$.

$\mathrm{Su}$ itinerario internacional, habla igualmente de un hombre de mundo. Originario de Granada, se trasladó a Filipinas como misionero, donde permaneció por 15 años. Posteriormente se trasladó a México, luego a Guatemala y Honduras, lo que le valió el

\footnotetext{
${ }^{15}$ El texto es reproducido por Vicente de La Fuente, quien señala que el "original pertenece a José Vicente Caravantes". Sin embargo, no queda claro si este es el autor del texto o el dueño del ejemplar que reviso de la Fuente. A pesar de la cercanía con los impresos de la época, llama la atención que a diferencia del resto de los escritos antimasónicos, no existe ninguna mención de este en la literatura de la época.

16 "Verdadera cronología de los Maniqueos, que aun existen con el nombre de Franc-Masones", en Historia de las sociedades secretas antiguas y modernas en España, Vicente De La Fuente (Lugo: Imp. De Soto Freire), 423.

${ }^{17}$ El libro tuvo al menos cinco ediciones: una segunda el mismo año de 1752, una tercera en 1754 , una cuarta en 1794 y una quinta en 1814. Al respecto véase: Ferrer Benimeli, La masonería Española en el siglo XVIII (Madrid, Siglo XXI editores, 1986), 176.

${ }^{18}$ Relación de los méritos del R.P. Fr. Joseph Torrubia, Madrid, 5 de febrero de 1753, en el AGI, Indiferente, $238, \mathrm{~N}^{\circ} 7$.

${ }^{19}$ El libro de Torrubia es considerado el primer escrito en España sobre paleontología. Sus ideas, se centran en fenómenos como la naturaleza de los fósiles, a los cuales les atribuye su origen en el Diluvio universal, así como la existencia de gigantes, temática esta última que defiende en su obra "La gigantologia espagnola vendicata" de 1760. Debido al alcance que tuvo su obra científica, a pesar de las criticas, es considerado como uno de los "renovadores del ciencia en el siglo XVIII", Al respecto véase: Leandro Sequeiros, "José Torrubia y su aportación al método científico en paleontología": en Geogaceta 24 (1998): 226
} 
reconocimiento por sus servicios y contar con la "real protección del monarca" 20 . De regreso a España, en 1749, realizó un viaje a Roma, pasando por las ciudades de Rímini, Padua para terminar su viaje en París ${ }^{21}$.

Es muy probable que durante su periplo por Europa, particularmente por Italia, se haya puesto al tanto de la existencia de la masonería y haya tomado la decisión de escribir su obra "con el fin de instruir al público"22.

"Centinela contra francmasones", al igual como sucedió con las otras publicaciones hispánicas, estaba dedicado al Papa Benedicto XIV, y cumplía a cabalidad con todas las garantías legales. En términos doctrinarios, llama la atención el carácter "preventivo" que le atribuyen al libro. Así lo comprende al menos Fray Juan Picazo, Archivero General de la Orden- cargo que posteriormente ocupará Torrubia-, quien le concedió, inclusive, un tinte profético a su obra:

Centinela es, que atalayando, anteviendo, (más al caso) previniendo los males, que amenazan con la masonería, y sus detestables leyes, avisa, y pone de manifiesto en vulgar estilo perceptible a todos, que se acercan, o han llegado ya aquellos tiempos en gran manera peligrosos, de que hace mención san $\mathrm{Pablo}^{23}$.

Igualmente presente, es la figura del engaño, de la mentira, mecanismo a través del cual los masones encubren los verdaderos fines que la iglesia busca revelar. Para desarrollar esta idea, los teólogos utilizan metáforas lumínicas como contraposición a las sombras en las cuales la masonería se oculta: "Centinela, que es una luz clarísima, que alumbra para conocer, y detestar la masonería” o en el caso de Joseph Rey y Trigueros "Siendo el libro luz con que se desvanecen las pardas sombras que tenían ofuscadas las católicas inteligencias con las dudas, o ignorancias, sobre los errores, que practica la nueva secta de los Francmasones" 24 .

Por último, no deja de ser significativo el hecho de que incorporan la lucha contra los masones al credo católico en un plano normativo, como un combate del bien contra el mal, religándolo al principio de guerra santa:

Las nuevas infernales tropas de Franc-masones, que para hacer guerra a nuestra Católica religión ha levantado en estos tiempos, y alistado en sus negros estándares el Príncipe de las tinieblas, echando todo el esfuerzo de su astuta malicia, con nuevas invenciones, y ardiles de su obstinado tesón, compendiando

\footnotetext{
${ }^{20}$ Torrubia no estuvo ajeno de polémicas, lo que costó en una oportunidad su reclusión debido a sospechas de malversación de fondos. Probablemente fue por dicho motivo que obtuvo los honores reales, así como la protección papal, las cuales recibió como un medio de vindicación ante las injurias que se habían desatado en su contra. Al respecto véase: Ferrer Benimeli, La Masonería española, 178.

${ }^{21}$ Al respecto véase: Leandro Sequeiros, "Tercer centenario del nacimiento de José Torrubia (16981761): viajero, naturalista y paleontólogo", Revista Española de Paleontología 13 (1998): 288.

${ }^{22}$ Relación de los méritos, f.2.

${ }^{23}$ José Torrubia, Centinela contra francmasones. Discurso sobre su origen, instituto, secreto y juramento. Descubrese la cifra con que se escriben y las acciones, señales, y palabras con que se conocen (Madrid: Imprenta de Don Agustín de Gordejuela y Sierra, Calle de los Preciados, 1752), 18-19.

24 Torrubia, Centinela contra francmasones, 26.
} 
en ellos los más de los errores de las Sectas antiguas, y añadiendo su maligna sagacidad otros, con nuevos disfraces, y coloridos, para que engañados de las aparentes comodidades, y terrenos gustos, que ofrecen a los mundanos, muy conformes a sus ciegos sensuales apetitos ${ }^{25}$.

Centinela contra Francmasones, presentado por los teólogos que avalaron su publicación, es un tratado preventivo que busca impedir el ingreso de la masonería al imperio español. Representa a los masones como una nueva secta, a la cual describe como "serpientes" y a sus ideas como "veneno" siendo el impreso el antídoto para su cura.

La obra propiamente tal, al igual que los libros que circularon en Europa en la década de 1740, es un compilado de textos compuesto de las autorizaciones y respaldos políticos y religiosos, un discurso prologético, las reproducciones de las bulas de Clemente XII y Benedicto XIV, el decreto Real que prohíbe la masonería en el Imperio español y la pastoral de José María Justiniani.

En lo relativo al texto prologético, que en rigor es el único aporte inédito al debate, Torrubia hace gala de su erudición incorporando una parte importante de la bibliografía existente en la época.

Es así que su trabajo se basa fundamentalmente en las Constituciones de Anderson, "Le secret des francs-maçons écrasé", "Cérémonies et coutumes religieuses de tous les peuples du monde" del abate Banier y "Le secret des francs-maçons trahi" del abate Larudan ${ }^{26}$.

Joseph Torrubia, reproduce aquellos aspectos que sean de utilidad a su obra, dotándolos de un nuevo sentido.

En términos de contenido, el texto de Torrubia sintetiza y expurga la obra de Larudan con la finalidad de refutar los principios masónicos. Destaca su carácter herético, enfatiza que su origen está en Inglaterra y que fue una invención de Oliverio Cromwel. Posteriormente, reproduce algunos elementos de los rituales, las palabras y el alfabeto con que se comunican los masones, a los cuales describe de la siguiente manera: "Este es su sistema, y todo cuanto sus catecismo contienen debajo de esta clave, respira herejía, temeridad, sacrilegio, superstición, y merece una impugnación seria, la que te prometo con el favor Divino"27.

Al igual que la mayoría de los escritos católicos contra la masonería, ataca la existencia del juramento, la reunión de personas de diferente credo y condición social, así como la sospecha de sodomía entre sus miembros. Refiriéndose al juramento señala: "El juramento de los francmasones es una real, y verdadera profanación del Sacrosanto

\footnotetext{
${ }^{25}$ Torrubia, Centinela contra francmasones, 26.

${ }^{26}$ Este último, fue el único libro relacionado con la masonería que fue incorporado al índice de libros prohibidos en España. Al respecto véase: Marcelin Defourneaux, Inquisición y censura de libros en la España del siglo XVIII (México DF: Ed. Taurus, 1973), 221.

${ }^{27}$ Torrubia, Centinela contra francmasones, 56.
} 
nombre de Dios; y por consecuencia un acto tan detestable, que a el que lo cumple hace digno de la pública, y común execración" 28 .

$\mathrm{Y}$ frente al presunto indiferentismo religioso:

Vemos concurrir en las logias de los francmasones grandes, pequeños, plebeyos y nobles, literatos, e idiotas de todas naciones, religiones, y naturales. Conviven en su sistema luteranos, calvinistas, ateístas, y judíos(...) con hombres reputados por honestos se congregan otros criminosos, impíos, y de ninguna honestidad. Admitese también a la dicha Hermandad la gente más soez, vil, y baja de la República $^{29}$.

Por último, el autor sintetiza en 16 puntos aquellos aspectos que se conocen de la masonería, y que según él, bastarían para condenarla. Entre estos destacan el despreciar los sacramentos y leyes de la Iglesia; insultar y maldecir a la potestad eclesiástica; despreciar la comunión y morir sin sacramentos; comer carne en días prohibidos y beber en demasía. En síntesis, para el autor el "libertinaje" ${ }^{30}$ constituye el signo externo más representativo del masón.

En términos estructurales, la obra realiza una fusión entre el impreso católico y la tradición de las "exposures" británicas y francesas, revelando los secretos de los masones, claro está, de forma debidamente expurgada, al mismo tiempo de entregar información hasta ese entonces desconocida en España acerca de las máximas masónicas.

Cierra el primer ciclo de escritos referentes a la Masonería el célebre Jerónimo de Feijoo, quien le dedicó una de sus "Cartas eruditas y curiosas". A diferencia de todos los autores anteriores, que por lo demás son desautorizados por el mismo Feijoo, analizó la existencia de la masonería de forma desdramatizada y, sin dejar de condenarlos, desmintió algunas creencias generalizadas sobre ellos. En primer lugar, reconoció que "nada sabe con certeza" de los masones, pero consideró como "justísimos" los decretos que prohíben sus juntas, específicamente los emitidos por los papas. Relativizó su maldad inherente, pero no negó la posibilidad que entre ellos hayan algunos que deseen atentar contra la religión o el Estado ${ }^{31}$.

\footnotetext{
${ }^{28}$ Torrubia, Centinela contra francmasones, 79.

${ }^{29}$ Torrubia, Centinela contra francmasones, 82.

${ }^{30}$ Un texto publicado en Bélgica el mismo año, vincula a la masonería con Epicúreo, "el dios del ateísmo y del libertinaje" y define a este último como "gente que no le presta atención al culto divino, que no frecuentan las iglesias, y que hacen actos de religión por motivos puramente humanos". Al respecto véase: Pierre des Hondt, Les vrais jugement sur la société des Francs-Maçons. Ou l'on rapporte un détail abrégé de leurs Statuts: ou l'on fait voir ensuite combien ces Maximes sont contraires à celles de la Religion (Bruxelles, 1752), 23.

${ }^{31}$ Jerónimo de Feijoo, Cartas eruditas y curiosas en que, por la mayor parte se continua el designio del Theatro critico universal, impugnando, o reduciendo a dudosas, varias opiniones comunes, dedicadas opciones comunes. Dedicadas a la Reyna nuestra señora doña María Bárbara de Portugal, por mano del excelentísimo señor marques de la ensenada, caballero del toyson de oro, de Consejo de Estado, Secretario del Despacho Universal, de Guerra, Marina, Indias, Hacienda. Escritas por el muy ilustre senior don fray Benito Gerónimo Feijoo, maestro general de la religión de San Benito, del consejo de su
} 
En lo relativo al secreto, duda de su existencia, ya que considera casi imposible de que nadie lo haya revelado en su lecho de muerte. Igualmente, relativiza la sospecha de herejía de la cual postula, más bien, que se trata de un simple embuste. Aun así, concibe las juntas masónicas como análogas a las bacanales y por lo tanto justifica su prohibición, ya que estas "a la corta o a la larga conspiran contra la religión o el Estado",32.

Para Feijoo, los masones serían el equivalente a un duende. Destaca que entre estos existen de dos tipos: los que "traversean solo por traversear" y aquellos "que lo hacen, con algún intento perjudicial y depravado" en el caso de los masones "Los más eran unos duendes burlones, que se divertían a cuenta de los que metían en cavilaciones, y recelos, y entre estos habría otros algunos Duendes malévolos, cuya mira sería infeccionar a todos los asociados con algunas máximas perniciosas",33.

En síntesis, la primera generación de impresos antimasónicos hispánicos, centraron su argumentación en aspectos teológicos forjando una representación del masón como un individuo libertino e irreligioso y como una manifestación moderna de las sectas y herejías bíblicas. Se trató fundamentalmente de una producción literaria realizada por sacerdotes, y al parecer, destinada para ellos mismos, como un mecanismo pedagógico para impedir el ingreso y propagación de la masonería al Imperio español.

\section{Agentes de los Filósofos}

Por algún motivo durante la segunda mitad del siglo XVIII el tema de la masonería desapareció en la producción del impreso hispánico. Probablemente los avances de la Ilustración durante el reinado de Carlos III, donde la difusión de las obras e ideas de los filósofos adquirieron mayor relevancia, cambiaron el eje de atención de la literatura eclesiástica. De hecho, los sectores tradicionalistas se hicieron parte del combate contra los filósofos y a partir de la década de 1770 comenzaron a producir un tipo de literatura local fuertemente influenciada por la traducción de obras francesas e italianas.

España asimiló de esta manera la critica a la filosofía moderna, pero igualmente la hizo suya ${ }^{34}$, otorgándole un sentido de "guerra santa" a la usanza del combate que por la pureza de la fe impulsaron durante los siglos XVI y XVII contra moros, judíos y

majestad (Tomo cuarto, segunda impresión, con privilegio, Madrid: Imprenta de Don Eugenio Bieco, frente de la del papel sellado, calle del Barco año 1754), 194-209.

${ }^{32}$ Feijoo, Cartas eruditas y curiosas, 233.

${ }^{33}$ Feijoo, Cartas eruditas y curiosas, 233.

${ }^{34}$ Herrero tiende a otorgarle un carácter exclusivamente extranjero a las ideas anti-ilustradas que ingresaron a España. No obstante, el hecho de que se trate de traducciones, en las cuales son incorporados largos parajes contingentes a la historia española, hace que la producción local adquiera un carácter autóctono. Véase: Javier Herrero, Los orígenes del pensamiento reaccionario español (Madrid: Alianza, 1998). 
protestantes $^{35}$. De este modo, la Europa de las luces, encarnada por los filósofos, concentró gran parte de los ataques eclesiásticos de quienes comenzaban a defender la tradición española de las innovaciones en materia de pensamiento.

Detrás de estas medidas, estaba presente el proyecto de defender la pureza española y evitar con ello la disolución social. Así quedó establecido, por ejemplo, en la nota que el sacerdote Nicolás de Aquino introdujo en 1777 a su traducción de la obra de Nicolás Bergier:

Pero de a poco a esta parte abunda nuestra España de unos hombres iniciados en el Deísmo y Materialismo; y este contagio se va apoderando de modo de los corazones de algunos, que a no mediar la solicitud y celo de nuestro Católico Monarca, la vigilancia de los respetables pastores y el santo infatigable celo del Tribunal de la Fe, podría temerse que se hiciera más general la epidemia ${ }^{36}$.

Pero más significativo aún, fue el hecho de que el masón pasó a mimetizarse con la figura del filósofo, convirtiéndose en sinónimo y componente del conjunto de males que, según la literatura anti-ilustrada, comenzaba a aquejar a España.

Ejemplo de ello lo encontramos en algunos parajes de los estudios introductorios de las traducciones del mercedario Pedro Rodríguez Morzo, las cuales dan cuenta de esta mutación conceptual:

Yo llegué a pensar que la existencia de los irreligionarios era tan problemática, como la de los Franc-Masones, de los Agoreros, Brujas y Hechiceros. Así como estos infelices se intitulan, o los llaman tales, porque ellos querrían serlo, discurría yo lo mismo que los candidatos del espinosismo. Pero ya estoy persuadido a que en la descarada Cábala de los que están tocados del contagio de la Nueva Filosofía, se hace gala de su profesión, y existencia física, nada imaginaria $^{37}$.

La reivindicación de las luces provocó en un sector del clero español una respuesta de exaltación a la ortodoxia. Así, la apologética religiosa durante la segunda mitad del siglo tendió a radicalizarse para emprender una cruzada contra el

\footnotetext{
35 Véase al respecto la obra de Javier Herrero, Los orígenes del pensamiento reaccionario español (Madrid: Edicusa, 1971).

${ }^{36}$ Nicolás Bergier, El Deísmo refutado por si mismo o el examen de los principios de incredulidad esparcidos en las diversas obras de M. Rousseau en forma de cartas. Su autor M. Bergier, doctor en teología de la Academia de las ciencias, Bellas Letras y Artes de la Ciudad de Besanzon, Canónigo de Paris (Traducido al castellano e ilustrado con curiosas notas por el P. M. F. Nicolás de Aquino, del Orden de los Mínimos, en el convento de nuestra Señora de la Victoria de Granada, Madrid, 1777).

${ }^{37}$ Anónimo, El oráculo de los nuevos filósofos, M. Voltaire, impugnado y descubierto en sus errores por sus mismas obras, en dos tomos escritos en francés por un anónimo y traducidos el español por el R. $P$. Mro. Fr. Pedro Rodríguez Morzo, Comendados que ha sido en los conventos de Toledo y Madrid, del real Orden de la Merced Calzada, predicador del Rey nuestro señor y su censor de libros (Madrid: Imprenta de Gabriel Ramírez, Madrid, 1769), II.
} 
materialismo y cualquier atisbo de incredulidad o tolerancia religiosa ${ }^{38}$. De hecho, las ideas filosóficas ya eran vistas como un germen de descomposición social, tal como lo advierte Fernando Zevallos y Mier, quien examina los perjuicios que los filósofos traerían al Imperio español.

Además de la impiedad y de la irreligión que dicha filosofía predica, va también a revolver el orden público, a derribar a los soberanos, y a disipar a los magistrados y gobiernos establecidos, y si pudiera, a destruir a la humanidad ${ }^{39}$.

Al igual que Rodríguez Morzó, Zeballos incorpora la producción de los filósofos de las luces a la tradición bíblica católica, identificándolos como deístas, ateos y libertinos. Si bien su genealogía se remonta a un pasado lejano, identifica como punto de partida a la reforma protestante "la época más funesta en la historia de la religión" "

Resultan igualmente relevantes las definiciones que propone para los deístas y libertinos, debido a que estas, dado su alto nivel de generalidad, calzan perfectamente con la representación social del masón. Refiriéndose a los deístas Zevallos plantea:

Todos aquellos que viven sin alguna ley; sin piedad, aun natural; sin religión. Aunque no nieguen la idea de un Dios; pero le niegan la providencia sobre las cosas humanas, también le niegan algún culto determinado, quieren que cada uno lo nombre según su capricho, sin otra regla, no ceremonia, no ofrendas, no por alguna forma establecida. En este último estado son llamados Deístas, o Libertinos, o indiferentes o Filósofos. Todas estas voces son sinónimas ${ }^{41}$.

Y si bien filósofos, deístas y libertinos para el autor eran lo mismo, en el caso de los libertinos pone un énfasis en su predisposición hacia el placer: "Porque rompiendo el vinculo de toda sociedad, despreciaban el matrimonio, y se daban a la poligamia y al vago comercio entre los dos sexos (...) todos los que se arrojan a una libertad desenfrenada en pensar, decir, y obrar todo lo que les es agradable"42.

Más significativo que los puntos en común que los enemigos de las luces españoles veían en todas las "sectas" modernas, es la identificación categórica de la masonería como una más de ellas:

No desmerecen el lugar entre tantas clases de libertinos aquellos hombres oscuros y embozados, nombrados Francmasones. Acerca de los Francmasones se han aventurado ya diversas opiniones en varios escritos que se han divulgado

\footnotetext{
${ }^{38}$ Francisco Sánchez-Blanco, El absolutismo y las luces en el reinado de Carlos III (Madrid: Marcial Pons, 2002), 222.

${ }^{39}$ Fernando de Zeballos, La falsa filosofía o el ateísmo, deísmo, materialismo, y demás nuevas sectas convencidas de crimen de Estado contra los soberanos y sus regalías, contra los magistrados y potestades legitimas. Se combaten sus máximas sediciosas, y subversivas de todo sociedad y aun de la humanidad (Madrid: Imprenta de D. Antonio de Sancha, 1775), 75.

${ }^{40}$ Zeballos, La falsa filosofia, 75.

${ }^{41}$ Zeballos, La falsa filosofia, Vol. II, 11.

${ }^{42}$ Zeballos, La falsa filosofía, Vol. II, 76.
} 
contra ellos. El titulo de Francmasón no significa más que un social libre o libertino $^{43}$.

Zeballos, sin embargo, llega aun más lejos y vincula todos estos aspectos religiosos con la política. Para el autor, las "sectas" tienen una finalidad criminal y buscan atentar contra el poder, de ahí que los monarcas europeos deberían intervenir decididamente para su completa erradicación ${ }^{44}$ :

Ellos son reos públicos de todas las leyes, y de todo crimen de Estado: que por instituto, y por obligación de su secta son rebeldes a los reyes, a los magistrados $\mathrm{y}$ a todas las potestades ordenadas por Dios: que por principio de sus sistemas intentan disipar toda sociedad y turban todos los gobiernos establecidos, y aun la economía, y paz de todas las familias: por fin, que son los enemigos comunes de la humanidad y tiran a destruirla desde el nacimiento de los hombres hasta el suicidio $^{45}$.

En una línea análoga se encuentra el sacerdote Antonio Joseph Rodríguez, quien de manera aun más categórica, unifica en los masones a todas las sectas modernas:

Los que poco ha se gloriaban de Franc-masones, o libres edificadores, son estos mismos incrédulos, a quienes plació investirse de este nombre más disimulado, para ocultar el infame de Deístas, o ateístas. Las señales que nos muestran su esencia, todas son idénticas, si consultamos la doctrina de unos y otros: y la misma debiera ser la providencia de los soberanos y de sus ministros, para hacer enmudecer o exterminar a los filósofos fuertes, libres pensadores, como fue con los muratores libres? El temor prudente contra la quietud del Estado, que fue sospecha por estos, todo lector sabe que es evidencia en cuanto a los libres pensadores, pues no se guardan de insultar en sus escritos a todo gobierno y soberanía $^{46}$.

De esta manera, un sector importante del clero se sumó a la cruzada europea contra las luces e hizo de caja de resonancia de los ataques que desde la Iglesia católica

\footnotetext{
${ }^{43}$ Zeballos, La falsa filosofía, Vol. II, 79.

${ }^{44}$ A pesar del aspecto novedoso de su obra, la autoridad política la recibió con recelo y procedió a su censura, lo que implicó, entre otras cosas, que el séptimo y último volumen no fuese publicado. En un informe que los censores realizaron sobre su persona, se refieren a él como "bajador, soberbio y desdeñoso, maldiciente e infamador, falso y revoltoso, sin fe ni verdad, que no tiene otro objeto que vengar el pesar que la hacen cuantos se oponen a sus ideas". Al respecto véase, Lucienne Domergue, "Un defensor del trono y del altar acusado de crimen anti-regalista: Fray Fernando Ceballos", Bulletin Hispanique 80, no. 3-4 (1978): 190-200.

${ }^{45}$ Zeballos, La falsa filosofía, Vol. II, 119.

${ }^{46}$ El Philotheo en conversaciones del tiempo escritas por el R. P. M. Don Antonio Joseph Rodríguez, monje cistirsense en el Real Monasterio de Santa María de Beruela; Doctor en Sagrada Teología; consultor de Cámara del Serenísimo Señor infante Don Luis; Teólogo y examinador de la Nunciatura; examinador Sinodal del Arzobispado de Toledo, y de los Obispados de Tarazona y Xaca, Socio de las Reales Academias de Sevilla, Matritense y Portopolitana (En Madrid: Imprenta Real de la Gazeta, 1776), 5 .
} 
se lanzaban contra los filósofos. Sin embargo, el "movimiento antifilosófico" a pesar de su apariencia religiosa y católica, no tenía unidad doctrinal ni una estratégica unívoca ${ }^{47}$.

Entre los autores "anti-ilustrados" más populares que circularon por España se encuentra el francés Louis- Antoine Caraccioli, de quien hacia fines de la década de 1770 ya se habían traducido una docena de sus obras. En lo referente a la masonería, aportó algunos elementos que si bien no fueron del todo novedosos, sirvieron para mantener vigente el tema y advertir de los peligros de la heterodoxia en España.

Todo esto nos debe convencer, que los francmasones no son sino unos hombres, que se juntan y que forman un cuerpo aparte con el único fin de divertirse; y el hecho es tanto más cierto, cuanto vemos millares de francmasones gemir en medio de sus necesidades, sin que ninguno de sus hermanos les socorra, por más que se jacten de ser caritativos. No es más real su caridad, que su secreto. Uno y otro engañan con el velo de un fingido misterio, que solo subsiste porque no tomamos el trabajo de profundizarlo. En efecto el secreto de los francmasones, esto es, de una multitud de hombres esparcidos por todas partes, entre los cuales, como en las demás sociedades, hay borrachos, indiscretos, lascivos e interesados, es imposible que se guarde ${ }^{48}$.

Gran parte de los escritores y traductores de estas obras fueron eruditos de importancia en la cultura hispánica. Se trataba fundamentalmente de doctores en teología, poliglotas con formación en leyes y ciencias, pero sobretodo, como el caso de Zeballos, grandes conocedores- y por ende consumidores- de la Enciclopedia y de los filósofos. Sus obras, no estaban destinadas al gran público, sino más bien, a brindar argumentos a las elites para combatir la innovación en materia de pensamiento. De allí la pertinencia de la metáfora epidémica, de la cual sus escritos buscan ser una "cura", cuando no, un "preservativo" para impedir el contagio.

En términos generales, los apologistas de la segunda mitad del siglo XVIII, constituyeron el brazo intelectual de la ortodoxia tradicionalista española y sentaron las bases del movimiento contrarrevolucionario, en la medida que actuaron como barrera de contención en el proceso de modernización que vivía España durante el reinado de Carlos III.

La gestación de dos bandos, uno tradicionalista y otro modernizador, abrió el camino para identificar a los ilustrados españoles, a pesar de su fe, como los representantes locales del deísmo y el libertinaje.

La masonería por su parte, si bien estaba lejos de concentrar las críticas de la ortodoxia, ya constituía un elemento aglutinador del conjunto de males modernos, como una forma de asociación entre filósofos y sectarios. Solo bastaba el advenimiento de la

\footnotetext{
${ }^{47}$ Didier Masseau, Les ennemis des philosophes. L'antiphilosophie au temps des Lumières (París : Albin Michel, 2010), 20.

${ }^{48}$ Louis- Antoine Caraccioli, El goce o posesión de sí mismo, trad. Francisco Mariano Nipho (Madrid: Miguel Escribano, 1777), 391.
} 
Revolución y la ocupación napoleónica para que el "masón", a pesar de su carácter espectral, se encarnara en el incipiente liberalismo hispánico y se convirtiera en el actor principal de un nuevo complot contra la Iglesia católica y la monarquía.

\section{Conclusión}

La figura del masón sirvió en el mundo hispánico como un arma de defensa contra la modernidad. A pesar de su modesta presencia durante el siglo XVIII, se desplegó todo un aparato propagandístico para evitar su implantación.

La misma naturaleza abstracta del masón, permitió atribuirle una seria de calificativos que fueron configurando a un enemigo externo que sirvió a su vez de referencia para identificar al enemigo interno.

Para ello, el pensamiento conservador recurrió en una primera instancia a la historia bíblica, de tal manera de encontrar en la tradición los indicios que le permitieran comprender los cambios de los cuales estaban siendo testigos.

De este modo, la construcción del enemigo como una alteridad extrema, permitió aislar aquellos elementos que según el pensamiento eclesiástico eran ajenos a la tradición, y al mismo tiempo sirvió para reafirmar la verdadera identidad española, al ponerla en oposición con el "otro".

El masón, entonces, fue construido sobre la base de calificativos que llevaron al extremo su naturaleza aberrante, fue identificado como una persona hipócrita, falsa y mentirosa, cuyos planes serían de carácter infernal y sus medios sanguinarios. Y debido a su falta de moral, sus actos serían criminales, impíos, infames, miserables y bestiales ${ }^{49}$.

El espectro de la masonería, debido al carácter abstracto que tuvo en el mundo hispánico, sirvió como elemento aglutinador de todos aquellos aspectos que resultaban incómodos en el pensamiento reaccionario. Llegada la Revolución, los sectores liberales y reformistas constituyeron la última síntesis con la que se dotó de contenido al espectro, el cual para entonces, ya estaba compuesto de herejes, libertinos, filósofos, jansenistas, calvinistas, deístas y ateos.

\section{Fuentes primarias}

Anónimo. El oráculo de los nuevos filósofos, M. Voltaire, impugnado y descubierto en sus errores por sus mismas obras, en dos tomos escritos en francés por un anónimo y traducidos el español por el R. P. Mro. Fr. Pedro Rodríguez Morzo, Comendados que ha sido en los conventos de Toledo y Madrid, del real Orden

\footnotetext{
${ }^{49}$ Philippe Munch, «La foule révolutionnaire, l'imaginaire du complot et la violence fondatrice: aux origines de la nation française (1789)», Conserveries mémorielles 8 (2010): 14.
} 
de la Merced Calzada, predicador del Rey nuestro señor y su censor de libros. Madrid: Imprenta de Gabriel Ramírez, 1769.

Bergier, Nicolás. El Deísmo refutado por si mismo o el examen de los principios de incredulidad esparcidos en las diversas obras de M. Rousseau en forma de cartas. Su autor M. Bergier, doctor en teología de la Academia de las ciencias, Bellas Letras y Artes de la Ciudad de Besanzon, Canónigo de Paris. Traducido al castellano e ilustrado con curiosas notas por el P. M. F. Nicolás de Aquino, del Orden de los Mínimos, en el convento de nuestra Señora de la Victoria de Granada. Madrid, 1777.

Caraccioli, Louis- Antoine. El goce o posesión de sí mismo. Traducido del francés en castellano por D. Francisco Mariano Nipho. Madrid: Miguel Escribano, 1777.

Cliquet, José Faustino. Juicio dogmático moral sobre las cinco proposiciones de la perniciosa secta de los que se llaman De Liberi Muratori, o Francs Masons, Todas heréticas y abominables, condenadas por el SS.P. Clemente XII. Año de 1738. Segunda edición, Madrid: Imprenta de la Viuda de Ibarra, Hijos y Compañía, 1787.

Feijoo Jerónimo. Cartas eruditas y curiosas, en que, por la mayor parte se continua el designio del Theatro critico universal, impugnando, o reduciendo a dudosas, varias opiniones comunes, dedicadas opciones comunes. Dedicadas a la Reyna nuestra señora doña María Bárbara de Portugal, por mano del excelentísimo señor marques de la ensenada, caballero del toyson de oro, de Consejo de Estado, Secretario del Despacho Universal, de Guerra, Marina, Indias, Hacienda. Escritas por el muy ilustre senior don fray Benito Gerónimo Feijoo, maestro general de la religión de San Benito, del consejo de su majestad. Tomo cuarto, segunda impresión, con privilegio, en Madrid: Imprenta de Don Eugenio Bieco, frente de la del papel sellado, calle del Barco año 1754.

Pi y Vila- Rasa, Joseph. Carta pastoral que escribió el ilustrissimo y Rmo. Señor Don Fr. Pedro Maria Giustiniani, Obispo de Ventimiglia en el Estado de Génova, en orden a la Sociedad de los Francmassones. Barcelona, 1751.

Zeballos, Fernando de. La falsa filosofía o el ateísmo, deísmo, materialismo, y demás nuevas sectas convencidas de crimen de Estado contra los soberanos y sus regalias, contra los magistrados y potestades legitimas. Se combaten sus máximas sediciosas, y subversivas de todo sociedad y aun de la humanidad. Madrid: Imprenta de D. Antonio de Sancha, 1775.

\section{Bibliografía}

Anónimo. Secoli Cristiani della Liguria, Tipografia Chirio e Mina. Torino, 1843.

Darton, Robert. Edición y subversión. Literatura clandestina en el Antiguo Régimen. México DF: Fondo de Cultura Económica, 2003. 
Ferrer Benimeli, José Antonio. La masonería Española en el siglo XVIII. Madrid: Siglo XXI editores, 1986.

Herrero, Javier. Los orígenes del pensamiento reaccionario español. Madrid: Alianza, 1998.

Masseau, Didier. Les ennemis des philosophes. L'antiphilosophie au temps des Lumières. París: Albin Michel, 2010.

Mestre, Antonio. "Muratori y la cultura". En La fortuna di L. A. Muratori. Atti del Convegno Internazionale di Studi Muratoriani. Modena: ed. Leo Olschki, 1972.

Munch, Philippe. "La foule révolutionnaire, l'imaginaire du complot et la violence fondatrice: aux origines de la nation française (1789)". Conserveries mémorielles 8 (2010).

Francovich, Carlo. Storia della Massoneria in Italia. Dalle origini alla rivoluzione francese. Firenze: La Nuova Italia, 1974.

Sánchez-Blanco, Francisco. El absolutismo y las luces en el reinado de Carlos III. Madrid: Marcial Pons, 2002. 